\title{
Applications of the Simple Multi-Fluid Model to Correlations of the Vapor-Liquid Equilibrium of Refrigerant Mixtures Containing Carbon Dioxide*
}

\author{
Ryo AKASAKA** \\ ** Faculty of Humanities, Kyushu Lutheran College \\ 3-12-16 Kurokami, Kumamoto 860-8520, Japan \\ E-mail: akasaka@klc.ac.jp
}

\begin{abstract}
This study presents a simple multi-fluid model for Helmholtz energy equations of state. The model contains only three parameters, whereas rigorous multi-fluid models developed for several industrially important mixtures usually have more than 10 parameters and coefficients. Therefore, the model can be applied to mixtures where experimental data is limited. Vapor-liquid equilibrium (VLE) of the following seven mixtures have been successfully correlated with the model: $\mathrm{CO}_{2}+$ difluoromethane (R-32), $\mathrm{CO}_{2}+$ trifluoromethane (R-23), $\mathrm{CO}_{2}+$ fluoromethane (R-41), $\mathrm{CO}_{2}+1,1,1,2-$ tetrafluoroethane (R-134a), $\mathrm{CO}_{2}+$ pentafluoroethane (R-125), $\mathrm{CO}_{2}+1$,1-difluoroethane (R-152a), and $\mathrm{CO}_{2}+$ dimethyl ether (DME). The best currently available equations of state for the pure refrigerants were used for the correlations. For all mixtures, average deviations in calculated bubble-point pressures from experimental values are within $2 \%$. The simple multi-fluid model will be helpful for design and simulations of heat pumps and refrigeration systems using the mixtures as working fluid.
\end{abstract}

Key words : Carbon Dioxide, R-32, R-23, R-41, R-134a, R-125, R-152a, Dimethylether, Equation of State, Equilibrium

\section{Introduction}

A simple multi-fluid model based on Helmholtz energy equations of state is presented. Vapor-liquid equilibrium (VLE) of refrigerant mixtures of carbon dioxide $\left(\mathrm{CO}_{2}\right)$ with difluoromethane (R-32), trifluoromethane (R-23), fluoromethane (R-41), 1,1,1,2-tetrafluoroethane (R-134a), pentafluoroethane (R-125), 1,1-difluoroethane (R-152a), or dimethyl ether (DME) are correlated with the model. The mixtures studied here have recently been considered as promising alternative refrigerants to overcome shortcomings in the case that their constituents are solely used as a pure working fluid.

For example, although pure $\mathrm{CO}_{2}$ has already been used as natural, nontoxic, and inflammable working fluid for heat pumps, one of main disadvantages is that this type of heat pumps needs to be operated at a very high pressure; typically 150 bar is the maximum operating pressure. Mixing with other refrigerants with lower boiling point can reduce the high operating pressure. On the other hand, due to large latent heat DME has found commercial use as a refrigerant. In addition, the GWP of DME is lower than that of $\mathrm{CO}_{2}$. However, its flammability is very high. Mixing of DME with nonflammable and low-GWP substances such as $\mathrm{CO}_{2}$ is particularly promising.

In order to evaluate performance of heat pumps and refrigeration systems using the mixtures, a certain thermodynamic property model, preferably an equation of state, for the mixtures is essential. Cubic equations of state such as the Peng-Robinson equation ${ }^{(1)}$ are often used for cycle evaluations because of their simple mathematical structures. However, cubic

*Received 9 Mar., 2009 (No. 09-0104) [DOI: 10.1299/jtst.4.159] 
equations of state should not be used for geometry design of compressors, heat exchangers, and piping components, because the equations have poor capability of predictions for liquid densities and calorific properties.

For the pure refrigerants, $\mathrm{CO}_{2}, \mathrm{R}-32, \mathrm{R}-23, \mathrm{R}-41, \mathrm{R}-134 \mathrm{a}, \mathrm{R}-125, \mathrm{R}-152 \mathrm{a}$, and DME, accurate wide-ranging equations of state explicit in the Helmholtz energy have already been published. This type of equations allows precise calculations of VLE, $p v T$ and other thermodynamic properties such as enthalpies, entropies, and heat capacities. If an appropriate mixture model based on the pure-fluid equations is given, accurate calculations for mixtures would be possible.

The multi-fluid model is considered as the best approach in coupling such accurate purefluid equations. In the last decade, rigorous multi-fluid models have been developed for several industrially important mixtures. These models have a complex form containing many parameters. For example, the Lemmon and Jacobsen model ${ }^{(2)}$ for HFC refrigerant mixtures has three interaction parameters and 4- or 8-term departure function. The Tillner-Roth and Friend model ${ }^{(3)}$ for ammonia + water mixture includes five interaction parameters and 14-term departure function.

For the mixtures studied here, however, it is impossible to develop such complex multifluid models, because experimental data of the mixtures is very limited. Experimental data available at the moment are not enough for optimization of many parameters. Alternatively, this study presents a simple multi-fluid model applicable to mixtures where experimental data is limited. The model (the simple multi-fluid model) has only three parameters: two binary interaction parameters and one parameter representing the departure function. The model can be used for VLE correlations as readily as cubic equations of state.

This study attempts to correlate the VLE of the seven mixtures using the simple multifluid model. Comparisons of calculation results are made with experimental values. The attempt in this study is the first step in establishment of accurate mixture models for the mixtures.

Nomenclature

$\underline{A}:$ molar Helmholtz energy, $\mathrm{J} / \mathrm{mol}$

$F_{12}$ : parameter representing the departure function

$k_{T}$ : binary interaction parameter

$k_{V}$ : binary interaction parameter

$M$ : molecular weight, $\mathrm{g} / \mathrm{mol}$

$p:$ pressure, $\mathrm{Pa}$

$p_{b, \text { cal }}:$ calculated bubble-point pressure, $\mathrm{Pa}$

$p_{c}:$ critical pressure, $\mathrm{Pa}$

$R$ : molar gas constant, $\mathrm{J} / \mathrm{mol} \cdot \mathrm{K}$

$T$ : temperature, $\mathrm{K}$

$T_{c}$ : critical temperature, $\mathrm{K}$

$T_{\text {red }}$ : reducing temperature, $\mathrm{K}$

$\underline{V}:$ molar volume, $\mathrm{m}^{3} / \mathrm{mol}$

$\underline{V}_{c}:$ critical molar volume, $\mathrm{m}^{3} / \mathrm{mol}$

$\underline{V}_{\text {red }}:$ reducing volume, $\mathrm{m}^{3} / \mathrm{mol}$

$x$ : mole fraction of second component

$\alpha$ : dimensionless Helmholtz energy

$\alpha^{\circ}$ : ideal-gas or ideal-gas mixture part of dimensionless Helmholtz energy

$\alpha^{r}$ : residual part of dimensionless Helmholtz energy

$\Delta \alpha^{r}:$ departure function

$\delta$ : inverse reduced volume

$\tau:$ inverse reduced temperature

$\omega:$ acentric factor 
Table 1 Fundamental constants of the pure refrigerants

\begin{tabular}{lcccccl}
\hline Pure fluid & $\begin{array}{c}M \\
{[\mathrm{~g} / \mathrm{mol}]}\end{array}$ & $\begin{array}{c}T_{c} \\
{[\mathrm{~K}]}\end{array}$ & $\begin{array}{c}p_{c} \\
{[\mathrm{MPa}]}\end{array}$ & $\begin{array}{c}V_{c} \\
{\left[\mathrm{dm}^{\frac{3}{3}} / \mathrm{mol}\right]}\end{array}$ & $\begin{array}{c}\omega \\
{[-]}\end{array}$ & Reference \\
\hline $\mathrm{CO}_{2}$ & 44.01 & 304.13 & 7.377 & 0.09412 & 0.2239 & Span and Wagner ${ }^{(6)}$ \\
$\mathrm{R}-32$ & 52.02 & 351.23 & 5.783 & 0.1226 & 0.2769 & Tillner-Roth and Yokozeki ${ }^{(7)}$ \\
$\mathrm{R}-23$ & 70.01 & 299.29 & 4.832 & 0.1330 & 0.2630 & Penoncello et al. ${ }^{(8)}$ \\
$\mathrm{R}-41$ & 34.03 & 317.28 & 5.897 & 0.1075 & 0.2004 & Lemmon and Span $^{(9)}$ \\
$\mathrm{R}-134 \mathrm{a}$ & 102.03 & 374.21 & 4.059 & 0.1993 & 0.3268 & Tilnner-Roth and Baehr ${ }^{(10)}$ \\
$\mathrm{R}-125$ & 120.02 & 339.17 & 3.618 & 0.2092 & 0.3052 & Lemmon and Jacobsen $^{(11)}$ \\
$\mathrm{R}-152 \mathrm{a}$ & 66.05 & 386.41 & 4.517 & 0.1795 & 0.2752 & Outcalt and McLinden $^{(12)}$ \\
$\mathrm{DME}$ & 46.07 & 400.3 & 5.341 & 0.1663 & 0.1970 & Ihmels and Lemmon $^{(13)}$ \\
\hline
\end{tabular}

Table 2 Helmholtz energy equations of state for the pure refrigerants

\begin{tabular}{|c|c|c|c|}
\hline Pure fluid & Authors & $\begin{array}{l}\text { Temperature range } \\
{[\mathrm{K}]}\end{array}$ & $\begin{array}{c}\text { Maximum pressure } \\
{[\mathrm{MPa}]}\end{array}$ \\
\hline $\mathrm{CO}_{2}$ & Span and Wagner ${ }^{(6)}$ & $216-1100$ & 800 \\
\hline R-32 & Tillner-Roth and Yokozeki ${ }^{(7)}$ & $136-435$ & 70 \\
\hline $\mathrm{R}-23$ & Penoncello et al. ${ }^{(8)}$ & $118-475$ & 120 \\
\hline $\mathrm{R}-41$ & Lemmon and $\operatorname{Span}^{(9)}$ & $130-425$ & 70 \\
\hline $\mathrm{R}-134 \mathrm{a}$ & Tilnner-Roth and Baehr ${ }^{(10)}$ & $169-455$ & 70 \\
\hline $\mathrm{R}-125$ & Lemmon and Jacobsen $^{(11)}$ & $172-500$ & 60 \\
\hline $\mathrm{R}-152 \mathrm{a}$ & Astina and Sato ${ }^{(14)}$ & $154-450$ & 60 \\
\hline DME & Ihmels and Lemmon ${ }^{(13)}$ & $131-525$ & 40 \\
\hline
\end{tabular}

\section{Superscripts}

$$
\begin{aligned}
& \circ: \text { ideal-gas part } \\
& b: \text { bubble point } \\
& r: \text { residual part }
\end{aligned}
$$

Subscripts

$$
\begin{aligned}
& c: \text { critical point } \\
& i: \text { component } i(i=1,2)
\end{aligned}
$$

\section{Simple multi-fluid model}

For a binary mixture, a multi-fluid model explicit in the Helmholtz energy is expressed as

$$
\frac{\underline{A}(T, \underline{V}, x)}{R T}=\alpha=\alpha^{\circ}(T, \underline{V}, x)+\alpha^{r}(\tau, \delta, x)
$$

where

$$
\begin{aligned}
& \alpha^{\circ}(T, \underline{V}, x)=(1-x) \alpha_{1}^{\circ}(T, \underline{V})+x \alpha_{2}^{\circ}(T, \underline{V})+(1-x) \ln (1-x)+x \ln x, \\
& \alpha^{r}(\tau, \delta, x)=(1-x) \alpha_{1}^{r}(\tau, \delta)+x \alpha_{2}^{r}(\tau, \delta)+\Delta \alpha^{r}(\tau, \delta, x), \\
& \tau=\frac{T_{\text {red }}(x)}{T},
\end{aligned}
$$

and

$$
\delta=\frac{\underline{V}_{\text {red }}(x)}{\underline{V}} .
$$

In Eq. (1), $\underline{A}$ is the molar Helmholtz energy of the mixture, $\alpha$ is the dimensionless Helmholtz energy, $R$ is the molar gas constant, $8.314472 \mathrm{~J} /(\mathrm{mol} \cdot \mathrm{K})^{(4)}, T$ is the temperature, $\underline{V}$ is the molar volume, and $x$ is the mole fraction of the second component. The dimensionless Helmholtz energy $\alpha$ is split into an ideal-gas part $\alpha^{\circ}$ depending on $T, \underline{V}$, and $x$, and a residual part $\alpha^{r}$ depending on the inverse reduced temperature $\tau$, inverse reduced volume $\delta$, and $x$. In Eqs. (2) and (3), $\alpha_{i}^{\circ}$ and $\alpha_{i}^{r}$ are the ideal-gas part and residual part of a pure-fluid equation of state, and $\Delta \alpha^{r}$ is the departure function representing the excess Helmholtz energy. 
Table 3 Experimental VLE data of the mixtures studied in this work

\begin{tabular}{|c|c|c|c|c|c|c|}
\hline \multirow[b]{2}{*}{ Author } & \multirow[b]{2}{*}{ Year } & \multirow[b]{2}{*}{ No. points } & \multicolumn{3}{|c|}{ Range } & \multirow{2}{*}{$\begin{array}{c}\mathrm{AAD}^{*} \\
{[\%]}\end{array}$} \\
\hline & & & $T[\mathrm{~K}]$ & $p[\mathrm{MPa}]$ & $x_{\mathrm{CO}_{2}}$ & \\
\hline $\mathrm{CO}_{2}+\mathrm{R}-32$ & & & & & & \\
\hline Adams and Stein ${ }^{(15)}$ & 1971 & 55 & $222-283$ & $0.1-4.5$ & $0-1$ & 0.94 \\
\hline Rivollet et al. ${ }^{(16)}$ & 2004 & 58 & $283-343$ & $1.1-7.5$ & $0-1$ & 1.4 \\
\hline $\mathrm{CO}_{2}+\mathrm{R}-23$ & & & & & & \\
\hline Roth et al. ${ }^{(17)}$ & 1992 & 42 & $254-293$ & $1.5-5.6$ & $0.047-0.937$ & 0.47 \\
\hline $\mathrm{CO}_{2}+\mathrm{R}-41$ & & & & & & \\
\hline Holcomb et al. ${ }^{(18)}$ & 1997 & 37 & $218-290$ & $0.31-5.3$ & $0-1$ & 0.87 \\
\hline $\mathrm{CO}_{2}+\mathrm{R}-134 \mathrm{a}$ & & & & & & \\
\hline Duran-Valencia et al. ${ }^{(19)}$ & 2002 & 30 & $252-293$ & $0.13-2.0$ & $0-0.867$ & 1.7 \\
\hline Silva-Oliver et al. ${ }^{(20)}$ & 2002 & 23 & $330-354$ & $2.0-7.1$ & $0.066-0.745$ & 2.0 \\
\hline Lim et al. ${ }^{(21)}$ & 2008 & 37 & $323-343$ & $1.7-7.0$ & $0.092-0.663$ & 2.0 \\
\hline $\mathrm{CO}_{2}+\mathrm{R}-125$ & & & & & & \\
\hline Jeong et al. ${ }^{(22)}$ & 2007 & 22 & $313-333$ & $2.0-6.5$ & $0-0.782$ & 0.61 \\
\hline $\mathrm{CO}_{2}+\mathrm{R}-152 \mathrm{a}$ & & & & & & \\
\hline Madani et al. (23) & 2008 & 64 & $258-343$ & $0.14-7.6$ & $0-1$ & 0.78 \\
\hline $\mathrm{CO}_{2}+\mathrm{DME}$ & & & & & & \\
\hline Tsang and Streett ${ }^{(24)}$ & 1981 & 163 & $273-386$ & $0.26-7.9$ & $0-0.915$ & 1.5 \\
\hline Jónasson et al. ${ }^{(25)}$ & 1995 & 55 & $280-320$ & $0.42-6.8$ & $0-0.858$ & 0.98 \\
\hline Laursen et al. ${ }^{(26)}$ & 2002 & 27 & $298-320$ & $0.60-7.3$ & $0-0.848$ & 2.7 \\
\hline
\end{tabular}

${ }^{*}$ Average absolute deviation of calculated bubble-point pressures

Table 4 Experimental pvT data of the $\mathrm{CO}_{2}+\mathrm{R}-32$ and $\mathrm{CO}_{2}+\mathrm{R}-125$ mixtures

\begin{tabular}{lccccccc}
\hline Author & Year & No. points & $T[\mathrm{~K}]$ & $p[\mathrm{MPa}]$ & $\begin{array}{l}\text { Range } \\
v\left[\mathrm{dm}^{3} / \mathrm{mol}\right]\end{array}$ & $x_{\mathrm{CO}_{2}}$ & $\begin{array}{c}\mathrm{AAD}^{*} \\
{[\%]}\end{array}$ \\
\hline $\begin{array}{l}\mathrm{CO}_{2}+\mathrm{R}-32 \\
\text { Nicola et al. }\end{array}{ }^{(27)}$ & 2002 & 65 & $288-358$ & $1.4-4.9$ & $0.47-1.4$ & $0.101-0.802$ & 0.82 \\
\hline $\mathrm{CO}_{2}+\mathrm{R}-125$ & & & & & \\
Nicola et al. & & & & \\
(27) & 2002 & 65 & $290-363$ & $1.6-4.7$ & $0.50-1.1$ & $0.301-0.824$ & 0.17 \\
\hline
\end{tabular}

The fundamental constants of the pure refrigerants are summarized in Table 1. Purefluid equations of state used in this study and their valid ranges are tabulated in Table 2. All equations of state are expressed explicit in the Helmholtz energy.

The reducing parameters $T_{\text {red }}$ and $\underline{V}_{\text {red }}$ in Eqs. (4) and (5) are normally given as a function of composition. The simple multi-fluid model uses the following expression:

$$
T_{\text {red }}(x)=(1-x)^{2} T_{\mathrm{c}, 1}+x^{2} T_{\mathrm{c}, 2}+k_{T} x(1-x)\left(T_{\mathrm{c}, 1}+T_{\mathrm{c}, 2}\right)
$$

and

$$
\underline{V}_{\text {red }}(x)=(1-x)^{2} \underline{V}_{c, 1}+x^{2} \underline{V}_{c, 2}+k_{V} x(1-x)\left(\underline{V}_{c, 1}+\underline{V}_{c, 2}\right),
$$

where $k_{T}$ and $k_{V}$ are binary interaction parameters. This expression was originally used by Tillner-Roth et al. ${ }^{(5)}$ for HFC refrigerant mixtures.

The departure function $\Delta \alpha^{r}$ appearing in Eq. (3) is introduced to obtain better agreement with experimental data. Generally, $\Delta \alpha^{r}$ is represented as

$$
\Delta \alpha^{r}(\tau, \delta, x)=x(1-x) \Delta \varphi_{12}(\tau, \delta) .
$$

A functional form of $\Delta \varphi_{12}$ is determined empirically. In the past formulations ${ }^{(2),(3),(5)}$, for example, the expression

$$
\Delta \varphi_{12}(\tau, \delta)=\sum_{i=1}^{N_{1}} a_{i} \delta^{d_{i}} \tau^{t_{i}}+\sum_{i=N_{1}+1}^{N_{2}} a_{i} \exp \left(-\delta^{e_{i}}\right) \delta^{d_{i}} \tau^{t_{i}}
$$

has been successfully employed. The coefficients $a_{i}$ and exponents $d_{i}, e_{i}$, and $t_{i}$ are optimized by fitting to experimental data. This requires extensive experimental datasets including $p v T$ relation and calorific properties. As mentioned before, available experimental data of the mixtures studied here are very limited. 
Table 5 Optimized values for $k_{T}, k_{V}$, and $F_{12}$

\begin{tabular}{llrrr}
\hline 1st component & 2nd component & $k_{T}-1$ & $k_{V}-1$ & $F_{12}-1$ \\
\hline $\mathrm{CO}_{2}$ & $\mathrm{R}-32$ & -0.004240 & -0.02443 & 0.006902 \\
\cline { 2 - 5 } & $\mathrm{R}-23$ & -0.01796 & -0.003753 & 0.001147 \\
\cline { 2 - 5 } & $\mathrm{R}-41$ & 0.003402 & -0.002859 & 0 \\
\cline { 2 - 5 } & $\mathrm{R}-134 \mathrm{a}$ & -0.003423 & 0 & 0 \\
\cline { 2 - 5 } & $\mathrm{R}-125$ & -0.02851 & -0.01671 & 0.007158 \\
\cline { 2 - 5 } & $\mathrm{R}-152 \mathrm{a}$ & -0.007547 & -0.03755 & 0.01684 \\
\cline { 2 - 5 } & $\mathrm{D} M E$ & 0.01803 & 0 & -0.001715 \\
\hline
\end{tabular}

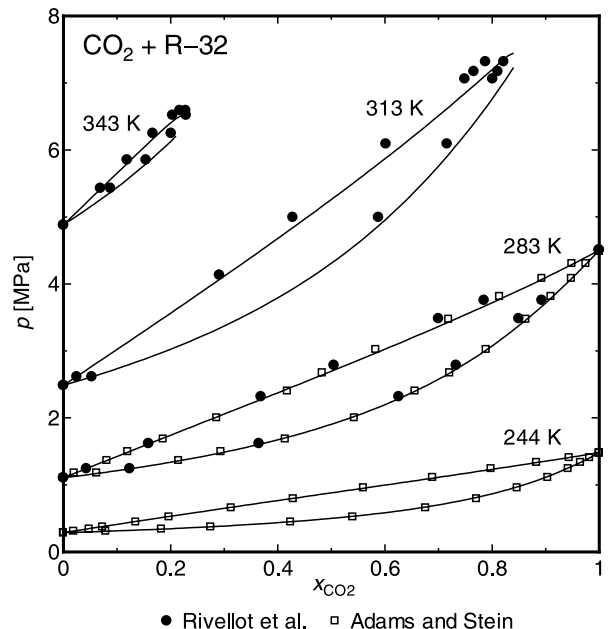

Fig. 1 VLE correlation of the $\mathrm{CO}_{2}+\mathrm{R}-32$ mixture with the simple multi-fluid model

In order to reduce the number of parameters that have to be optimized, the simple multifluid model uses the expression

$$
\Delta \alpha^{r}(\tau, \delta, x)=x(1-x)\left(F_{12}-1\right)\left[\alpha_{1}^{r}(\tau, \delta)+\alpha_{2}^{r}(\tau, \delta)\right],
$$

where $F_{12}$ is an adjustable parameter. No attempt has used this expression for $\Delta \alpha^{r}$. Equation (10) comes from the quadratic expression for $\alpha^{r}$ :

$$
\begin{aligned}
\alpha^{r}(\tau, \delta, x) & =\sum_{i=1}^{2} \sum_{j=1}^{2} x_{i} x_{j} \alpha_{i j}^{r}(\tau, \delta) \\
& =(1-x)^{2} \alpha_{1}^{r}(\tau, \delta)+x^{2} \alpha_{2}^{r}(\tau, \delta)+2 x(1-x) \alpha_{12}^{r}(\tau, \delta),
\end{aligned}
$$

where

$$
\alpha_{12}^{r}=\frac{F_{12}\left(\alpha_{1}^{r}+\alpha_{2}^{r}\right)}{2} .
$$

Equation (11) can be converted to the form

$$
\alpha^{r}=(1-x) \alpha_{1}^{r}+x \alpha_{2}^{r}+x(1-x)\left(F_{12}-1\right)\left(\alpha_{1}^{r}+\alpha_{2}^{r}\right) .
$$

\section{Results and discussion}

Experimental VLE data of the mixtures are summarized in Table 3. Only for the $\mathrm{CO}_{2}+$ R-32 and $\mathrm{CO}_{2}+\mathrm{R}-125$ mixtures, $p v T$ measurements are available. They are summarized in Table 4. No experimental data for heat capacities is available for all mixtures.

The simple multi-fluid model contains a total of three adjustable parameters, which are $k_{T}$ and $k_{V}$ in Eqs. (6) and (7), and $F_{12}$ in Eq. (10). They are simultaneously optimized by fitting procedure to experimental VLE data. This optimization process minimizes the objective function

$$
f=\sum_{i=1}^{N}\left(\frac{p-p_{b, \mathrm{cal}}}{p_{b, \mathrm{cal}}}\right)^{2}
$$






Fig. 2 Deviations in the molar volume of the $\mathrm{CO}_{2}+\mathrm{R}-32$ mixture calculated with the simple multi-fluid model from experimental value by Nicola et al. ${ }^{(27)}$

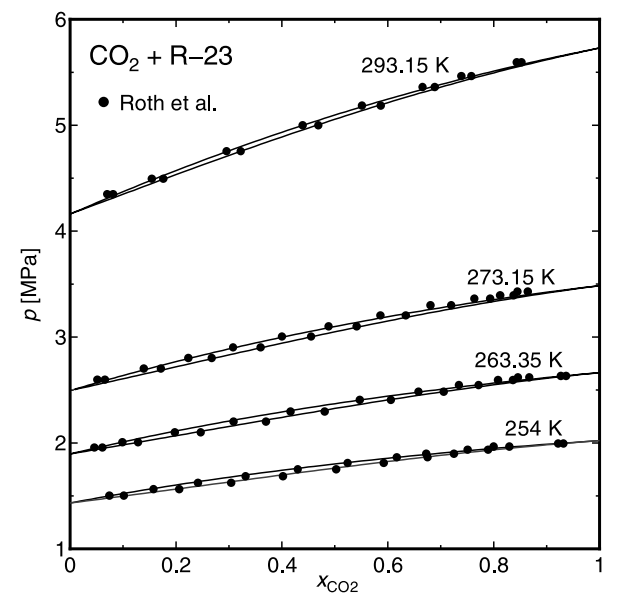

Fig. 3 VLE correlation of the $\mathrm{CO}_{2}+\mathrm{R}-23$ mixture with the simple multi-fluid model

using the quasi-Newton algorithm, where $p$ is a measurement for pressure and $p_{b, \text { cal }}$ is the bubble-point pressure obtained from the VLE calculations. Measurements $T$ and $x$ are used as input. Dew-point data are not used in the optimization process, because generally the VLE behaviors of mixtures with relatively weak nonideality can be reasonably represented by the fitting only to bubble-point data.

The optimized parameters for each mixture are tabulated in Table 5. The average absolute deviations (AAD) of calculated bubble-point pressures are shown in Table 3.

For the $\mathrm{CO}_{2}+\mathrm{R}-32$ mixture, the experimental VLE data by Adams and Stein ${ }^{(15)}$ and that by Rivollet et al. ${ }^{(16)}$ were used in the fitting procedure. Figure 1 is a graphical representation of the VLE correlation at $244 \mathrm{~K}, 283 \mathrm{~K}, 313 \mathrm{~K}$, and $343 \mathrm{~K}$. The simple multi-fluid model with the optimized parameters can well correlate the VLE at $244 \mathrm{~K}$ and $283 \mathrm{~K}$. Although the correlations at higher two temperatures show slight deviations from experimental values, they are at least qualitatively correct. The molar volumes of superheated vapor calculated using the optimized parameters were compared with the experimental values by Nicola et al. ${ }^{(27)}$. The comparison is shown in Fig. 2. The deviations in calculated molar volumes are within $\pm 2 \%$, and the AAD is $0.82 \%$ (shown in Table 4). The accuracy would be improved if the experimental $p v T$ data is included in the optimization process.

For the $\mathrm{CO}_{2}+\mathrm{R}-23$ mixture, the VLE correlation was made using the data by Roth et $\mathrm{al},{ }^{(17)}$ which is the only one published experimental data of the mixture. Figure 3 shows the correlation with the simple multi-fluid model. The VLE behavior of this mixture is characterized by a small difference in liquid and vapor composition. The simple multi-fluid model with optimized parameters successfully represents this behavior. The average absolute deviation of calculated bubble-point pressure is $0.47 \%$. The correlation is excellent.

For the $\mathrm{CO}_{2}+\mathrm{R}-41$ mixture, only data by Holcomb ${ }^{(18)}$ is available. Figure 4 shows the correlation at $230 \mathrm{~K}, 245 \mathrm{~K}, 260 \mathrm{~K}$, and $275 \mathrm{~K}$. The mixture also exhibits similar compositions 


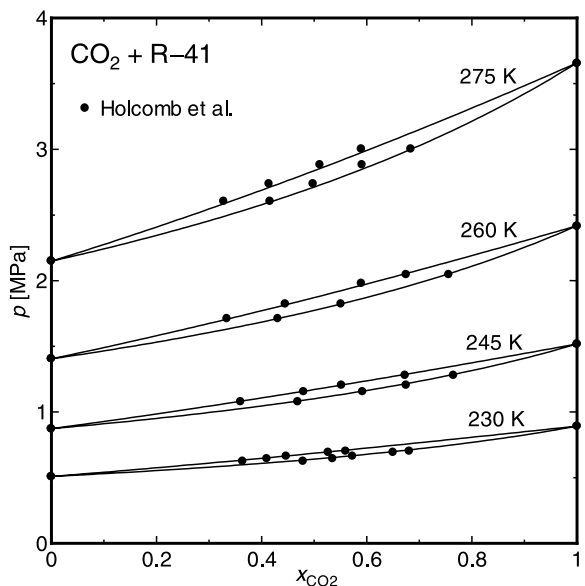

Fig. 4 VLE correlation of the $\mathrm{CO}_{2}+\mathrm{R}-41$ mixture with the simple multi-fluid model

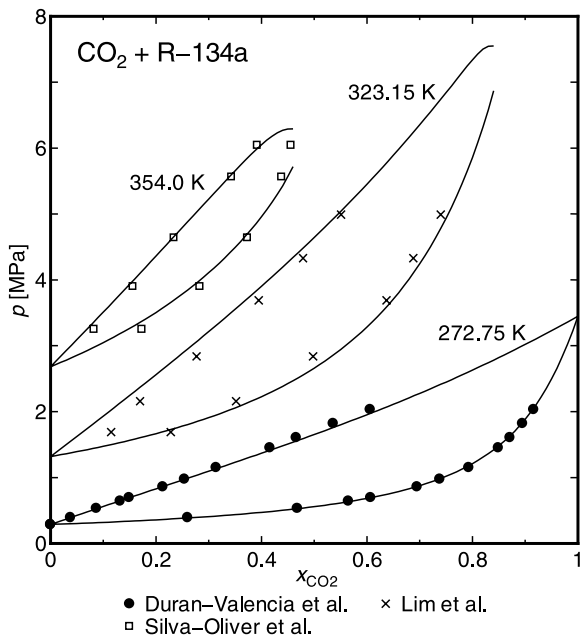

Fig. 5 VLE correlation of the $\mathrm{CO}_{2}+\mathrm{R}-134 \mathrm{a}$ mixture with the simple multi-fluid model

of liquid and vapor phases. Although the experimental data is restricted to middle range of composition, the correlation with the simple multi-fluid model agrees with the VLE behavior in the range. The average absolute deviation of calculated bubble-point pressure is smaller than $1 \%$.

For the $\mathrm{CO}_{2}+\mathrm{R}-134 \mathrm{a}$ mixture, three datasets of Duran-Valencia et al. ${ }^{(19)}$, Silva-Oliver et al. ${ }^{(20)}$, and Lim et al. ${ }^{(21)}$ were incorporated in the fitting procedure. During optimization the effects of $k_{V}$ and $F_{12}$ on the correlation was found to be extremely small. Therefore, only $k_{T}$ was optimized. The correlations at $272.75 \mathrm{~K}, 323.15 \mathrm{~K}$, and $354.0 \mathrm{~K}$ are shown in Fig. 5. At the temperatures the VLE correlations with the simple multi-fluid model are satisfactory. At $354.0 \mathrm{~K}$ the correlation well represents the data of Silva-Oliver et al. ${ }^{(20)}$ even in the close vicinity of the critical point.

For the $\mathrm{CO}_{2}+\mathrm{R}-125$ mixture, only data of Jeong et al. ${ }^{(22)}$ is available. Figure 6 shows the correlations at $313.15 \mathrm{~K}, 323.15 \mathrm{~K}$, and $333.15 \mathrm{~K}$. The temperatures are higher than the critical temperature of carbon dioxide. The correlations show good agreement with experimental values, even in the critical region. The average absolute deviation is fairly small $(0.61 \%)$. Comparison of the molar volumes calculated using the optimized parameters was made with the experimental values by Nicola et al. ${ }^{(27)}$. The result is shown in Fig. 7. The calculations are in excellent agreement with the experimental values. The AAD in calculated molar volumes 


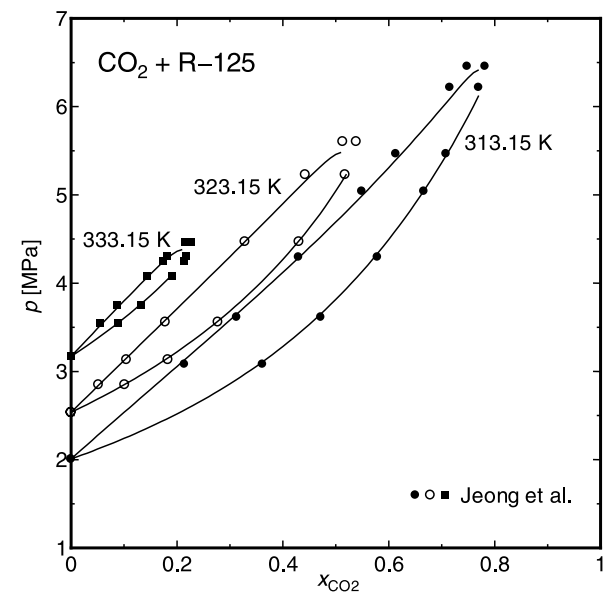

Fig. 6 VLE correlation of the $\mathrm{CO}_{2}+\mathrm{R}-125$ mixture with the simple multi-fluid model

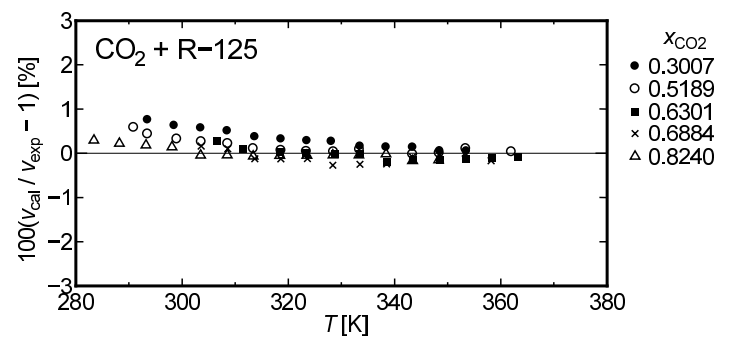

Fig. 7 Deviations in the molar volume of the $\mathrm{CO}_{2}+\mathrm{R}-125$ mixture calculated with the simple multi-fluid model from experimental value by Nicola et al. ${ }^{(27)}$

is $0.17 \%$ (shown in Table 4).

For the $\mathrm{CO}_{2}+\mathrm{R}-152 \mathrm{a}$ mixture, the data of Madani et al. ${ }^{(23)}$ is the only one published VLE measurement. The correlations at $258.44 \mathrm{~K}, 308.37 \mathrm{~K}$, and $343.20 \mathrm{~K}$ are represented in Fig. 8. The simple multi-fluid model with optimized parameters accurately correlates the VLE of the mixture; the average absolute deviation is $0.78 \%$. At $308.37 \mathrm{~K}$ the correlation is successful up to the critical point.

For the $\mathrm{CO}_{2}+$ DME mixture, the data of Tsang and Streett ${ }^{(24)}$ was used in the fitting procedure. The other two data (Jónasson et al. ${ }^{(25)}$ and Laursen et al. ${ }^{(26)}$ ) were used for evaluation of correlation performance. Since the effect of $k_{V}$ on the correlation was found to be extremely small, only $k_{T}$ and $F_{12}$ were optimized. Figure 9 shows the correlations at $288.2 \mathrm{~K}, 320.06 \mathrm{~K}$, and $377.57 \mathrm{~K}$. At lower two temperatures the simple multi-fluid model well describes the VLE behavior. However, at $377.57 \mathrm{~K}$ the model shows poor correlation in the critical region.

\section{Conclusion}

Vapor-liquid equilibrium of the mixtures of $\mathrm{CO}_{2}$ with R-32, R-23, R-41, R-134a, R-125, R-152a, or DME were correlated using the simple multi-fluid model coupled with the best currently available equations of state for the pure substances. Since the model has only three adjustable parameters, correlations with the model are as readily as those with cubic equations of state. For the seven mixtures, optimum parameters of the model were determined. With the parameters, the model can well represent the VLE of the mixtures except the critical region of the $\mathrm{CO}_{2}+$ DME mixture. In most cases the average deviations of bubble-point pressures calculated with the model are within $2 \%$. Poor capability in the critical region is not a crucial problem, because the conditions at which typical heat pumps and refrigeration systems are operated are considerably lower than the critical point of working fluid. For the establishment of more accurate wide-ranging mixture model, additional experimental data such as $p v T$ data 


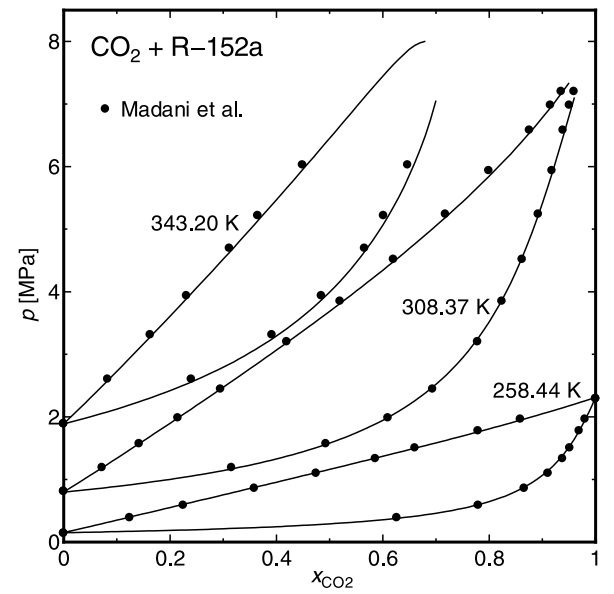

Fig. 8 VLE correlation of the $\mathrm{CO}_{2}+\mathrm{R}-152 \mathrm{a}$ mixture with the simple multi-fluid model

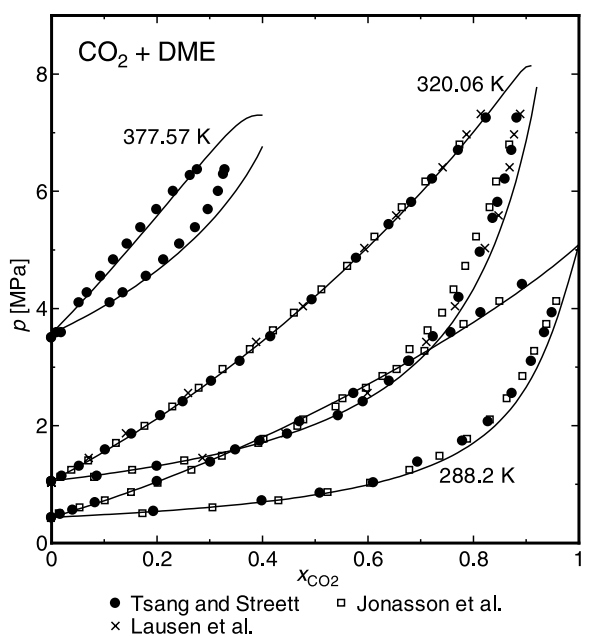

Fig. 9 VLE correlation of the $\mathrm{CO}_{2}+$ DME mixture with the simple multi-fluid model

and heat capacities are desired.

\section{References}

( 1 ) Peng, D.-Yu., Robinson, D. B., AIChE Journal, Vol.23 (1977), pp.137-144.

( 2 ) Lemmon, E.W., Jacobsen, R.T., Journal of Physical and Chemical Reference Data, Vol.33, No.3 (2004), pp.593-620.

( 3 ) Tillner-Roth, R., Friend, D. G., Journal of Physical and Chemical Reference Data, Vol.27, No.1 (1998), pp.63-96.

( 4 ) Mohr, P. J., Taylor, B. N., Journal of Physical and Chemical Reference Data, Vol.28, No.6 (1999), pp.1713-1852.

( 5 ) Tillner-Roth, R., Li, J., Yokozeki, A., Sato, H., Watanabe, K., Thermodynamic Properties of Pure and Blended Hydrofluorocarbon (HFC) Refrigerants, (1998), Japan Society of Refrigerating and Air Conditioning Engineers.

( 6 ) Span, R., Wagner, W, Journal of Physical and Chemical Reference Data, Vol.25, No.6 (1996), pp.1509-1596.

( 7 ) Tillner-Roth, R., Yokozeki, A., Journal of Physical and Chemical Reference Data, Vol.26, No.6 (1997), pp.1273-1328.

( 8 ) Penoncello, S. G., Lemmon, E. W., Shan, R. T., Journal of Physical and Chemical 
Reference Data, Vol.32, No.4 (2003), pp.1473-1499.

(9) Lemmon, E.W., Span, R., Journal of Chemical Engineering Data, Vol.51 (2006), pp.785-850.

(10) Tillner-Roth, R., Baehr, H. D., Journal of Physical and Chemical Reference Data, Vol.23, No.5 (1994), pp.657-729.

(11) Lemmon, E. W., Jacobsen, R. T., Journal of Physical and Chemical Reference Data, Vol.34, No.1 (2005), pp.69-108.

(12) Outcalt, S. L., and McLinden, M. O., Journal of Physical and Chemical Reference Data, Vol.25, No.2 (1996), pp.605-636.

(13) Ihmels, E. C., Lemmon, E. W., Fluid Phase Equilibria, Vol.260 (2007), pp.36-48.

(14) Astina, I.M., Sato, H., International Journal of Thermophysics, Nol.25, No.6 (2004), pp.1713-1733.

(15) Adams, R. A., Stein, F. P., Journal of Chemical Engineering Data Vol.16, No.2 (1971), pp.146-149.

(16) Rivollet, F., Chapoy, A., Coquelet, C., Richon, D., Fluid Phase Equilibria, Vol.218 (2004), pp.95-101.

(17) Roth, H., Peters-Gerth, P., Lucas, K., Fluid Phase Equilibria, Vol.73 (1992), pp.147166.

(18) Holcomb, C. D., Magee, J. W., Scott, J. L., Outcalt, S. L., Haynes, W. M., NIST Technical Note, 1397, (1997).

(19) Duran-Valencia, C., Pointurier, G., Valtz, A., Guibot, P., Richon, D. Journal of Chemical Engineering Data Vol.47, No.1 (2002), pp.59-61.

(20) Silva-Oliver, G., Galicia-Luna, L. A., Fluid Phase Equilibria, Vol.199 (2002), pp.213222.

(21) Lim, J. S., Park, J-Y., Lee, B-G., Lee, Y-W., Kim, J-D., Journal of Chemical Engineering Data Vol.44, No.6 (1999), pp.1226-1230.

(22) Jeong, K., Im, J., Lee, S., Kim H., Journal of Chemical Thermodynamics, Vol.39 (2007), pp.531-535.

(23) Madani, H., Valtz, A., Coquelet, C., Meniai, A. H., Richon, D., Journal of Chemical Thermodynamics, Vol.40 (2008), pp.1490-1494.

(24) Tsang, C. Y., and Streett, W. B., Journal of Chemical and Engineering Data, Vol.26, No.2 (1981), pp.155-159.

(25) Jónasson, A., Persson, O., and Fredenslund A., Journal of Chemical and Engineering Data, Vol.40, No.2 (1995), pp.296-300.

(26) Laursen, T., Rasmussen, P., and Andersen, S. I., Journal of Chemical and Engineering Data, Vol.47, No.2 (2002), pp.198-202.

(27) Nicola, G. D., Pacetti, M., and Polonara, F., Journal of Chemical and Engineering Data, Vol.47, No.5, (2002), pp.1145-1153. 